\title{
FENOMENA FULL DAY SCHOOL DALAM SISTEM PENDIDIKAN INDONESIA
}

\author{
Anggit Grahito Wicaksono \\ Universitas Slamet Riyadi Surakarta \\ Jl. Sumpah Pemuda No. 18 Kadipiro, Surakarta \\ E-mail: gara hito@yahoo.co.id
}

\begin{abstract}
Abstrak - Seiring dengan dinamika kehidupan yang kian menuntut kecepatan, ketepatan, kewaspadaan, perkembangan intelektual, emosional, spiritual dan kreatifitas siswa, metode konvensional dirasa belum dapat memenuhi kebutuhan pendidikan di masa sekarang dan mendatang sehingga muncullah konsep pendidikan baru bernama full day school. Full day school adalah sekolah yang pelaksanaan pembelajaran dilakukan selama sehari penuh dari pagi hingga sore dengan sebagian waktunya digunakan untuk pelajaran yang suasananya informal, tidak kaku, menyenangkan siswa, membutuhkan kreatifitas dan inovasi dari guru. Karakteristik dari full day school ini adalah mengedepankan akhlak dan prestasi akademik. Full day school bertujuan memberikan dasar yang kuat terhadap siswa dan mengembangkan minat dan bakat serta meningkatkan kecerdasan siswa dalam segala aspeknya.Keunggulan dari full day school dibandingkan dengan sekolah reguler adalah anak mendapatkan pendidikan utuh meliputi kognitif, afektif, dan psikomotorik, lebih banyak belajar dari pada bermain, produktivitas tinggi, serta potensi anak tersalurkan melalui kegiatan ekstrakurikuler di sekolah. Penelitian terkait full day school yang telah dilakukan menunjukkan bahwa full day school memiliki pengaruh yang positif terhadap peningkatan karakter, moral, akhlaq, maupun prestasi akademik siswa.
\end{abstract}

Kata kunci: fenomena pendidikan, full day school, sistem pendidikan

\begin{abstract}
Along with the dynamics of an increasingly demanding speed, accuracy, vigilance, intellectual, emotional, spiritual and creativity of students, the conventional methods are still not able to meet the educational needs of today and tomorrow so comes a new educational concept called full day school. Full day school is a school that is the implementation of learning done during a full day from morning to evening with most of the time used for lessons informal atmosphere, not stuffy, pleasant student, requires creativity and innovation of teachers. Characteristics of a full day of this school is to promote the character and academic achievement. Full day school aims to provide a strong basis to students and develop their interests and talents and increase the intelligence of the students in all aspects. The advantages of a full day school compared with regular schools is children get the whole education includes cognitive, affective, and psychomotor, learn more from the play, high productivity, and the potential of children channeled through extracurricular activities at school. Research related to full day school that has been done shows that the full day school has a positive effect on improvement of character, morals, morality, as well as students' academic achievement.
\end{abstract}

Keywords: education phenomenon, full day school, education system 


\section{PENDAHULUAN}

Pendidikan merupakan salah satu unsur fundamental dalam kehidupan manusia. Di Indonesia terdapat tiga jalur pendidikan yang dapat ditempuh yakni informal, formal, dan non formal. Sekolah sebagai lembaga pendidikan formal diharapkan memiliki kualitas yang baik sehingga mampu memenuhi kebutuhan masyarakat.

Seiring dengan dinamika kehidupan yang kian menuntut kecepatan, ketepatan, kewaspadaan, perkembangan intelektual, emosional, spiritual dan kreatifitas siswa, metode konvensional dirasa belum dapat memenuhi kebutuhan pendidikan di masa sekarang dan mendatang sehingga muncullah konsep pendidikan baru yang dinamakan full day school.Konsep full day school berbeda dengan sekolah reguler pada umumnya atau half day school. Half day school merupakan sekolah setengah hari yang berlangsung dari pagi sampai siang. Full day school merupakan sekolah sepanjang hari atau proses belajar mengajar yang dilakukan mulai pukul 06.45-15.00 dengan waktu istirahat setiap dua jam sekali (Baharudin, 2010: 221).

Peran orang tua dari hari ke hari semakin berkurang terutama di daerah perkotaan, baik oleh kesibukan mereka atau pergaulan anak-anak yang kian bebas. Dengan demikian, orang tua tidak bisa mendidik anaknya secara maksimal. Di lain pihak, sekolah dengan sistem pendidikan half day cenderung kurang bahkan tidak memperhatikan anak didiknya ketika berada di luar sekolah. Ketika anak sudah pulang dari sekolah maka tanggung jawab pendidikan ada di tangan orang tua atau keluarga.

Krisis moral yang terjadi pada bangsa Indonesia adalah sebagian permasalahan yang harus dicari solusinya. Hal ini dapat diketahui melalui media masa maupun media elektronik, bahkan dapat dilihat secara langsung perilaku penyimpangan yang dilakukan oleh pelajar. Komisi Nasional Perlindungan Anak (Komnas PA) mencatat sebanyak 2.008 kasus kriminalitas yang dilakukan anak usia sekolah terjadi di awal tahun 2012. Jumlah itu meliputi berbagai jenis kejahatan seperti pencurian, tawuran, dan pelecehan seksual yang dilakukan siswa SD hingga SMA (vivanews, 2012). Melihat fenomena bangsa yang seperti itu, sangatlah memprihatinkan. Hal tersebut merupakan akibat dari kurang terkontrolnya pergaulan anak dari pihak sekolah maupun pihak keluarga.

Munculnya pendidikan dengan pembelajaran program full day school diharapkan menjadi alternatif yang dapat memenuhi tuntutan pendidikan di masa sekarang. Melalui pembelajaran program full day school, peserta didik dibekali dengan nilai-nilai agama atau moralitas yang tinggi sehingga mereka tidak menjadi korban arus informasi global. Peran full day school, mampu menanamkan kebiasaan hidup mandiri, terampil dan menjunjung tinggi nilai-nilai moralitas. Hal ini dapat dilakukan sebab integrasi dan interaksi yang terjadi antara peserta didik dengan guru dalam pembelajaran, terjadi lebih intens dibandingkan dengan sekolah reguler, sehingga kegiatan dan aktifitas peserta didik dapat dikendalikan sesuai dengan jadwal yang telah ditentukan. Hal ini menunjukkan 
bahwa pengelolaan pembelajaran yang baik dan berkualitas akan mampu menentukan kualitas pembelajaran program full day school. Pengelolaan pembelajaran yang baik akan meningkatkan keberhasilan kualitas peserta didik.

Berdasarkan berbagai fenomena dan permasalahan di atas, artikel ini bertujuan untuk memberikan gambaran yang jelas tentang program full day school, menambah wawasan tentang penerapan full day school di Indonesia, dan menunjukkan keunggulan-keunggulan program full day school.

\section{PEMBAHASAN}

Menurut etimologi kata full day school berasal dari bahasa inggris. Full mengandung arti penuh, dan day artinya hari. Jika digabung, akan mengandung arti sehari penuh. Sedangkan school mempunyai arti sekolah (John M. Echols \& Hassan Shadily, 1996: 259). Baharudin (2010: 221) memberikan pengertian bahwa full day school adalah sekolah sepanjang hari atau proses belajar mengajar yang diberlakukan dari pagi hari sampai sore hari, mulai pukul 06.45-15.30 WIB, dengan durasi istirahat setiapdua jam sekali. Dengan demikian, sekolah dapat mengatur jadwal pelajaran dengan leluasa, disesuaikan dengan bobot mata pelajaran dan ditambah dengan pendalaman materi. Pengaturan jadwal mata pelajaran dan pendalaman merupakan hal yang diutamakan dalam full day school.

Sedangkan full day school menurut Sukur Basuki (2007: 4) adalah sekolah yang sebagian waktunya digunakan untuk program-program pembelajaran yang suasana informal, tidak kaku, menyenangkan bagi siswa dan membutuhkan kreatifitas dan inovasi dari guru. Hal ini Sukur berpatokan pada sebuah penelitian yang menyatakan bahwawaktu belajar afektif bagi anak itu hanya 3-4 jam sehari (dalam suasana formal) dan 7-8 jam sehari (dalam suasana informal). Sedangkan Sismanto (2007: 8) dalam artikel "Menakar Kapitalisasi Full Day School" juga mengungkapkan bahwa full day school merupakan sekolah sepanjang hari dengan proses pembelajaran yang dimulai dari pukul 06.4515.00 WIB dengan durasi istirahat setiap 2 jam mata pelajaran.

Berdasarkan pendapat ahli di atas, maka dapat disimpulkan bahwa full day school adalah sekolah yang dalam pelaksanaan pembelajaran dilakukan selama sehari penuh dari pagi hingga sore dengan sebagian waktunya digunakan untuk pelajatan yang suasananya informal, tidak kaku, menyenangkan bagi siswa dan membutuhkan kreatifitas dan inovasi dari guru. Sekolah dapat mengatur jadwal pelajaran dengan bebas dan leluasa, disesuaikan dengan bobot mata pelajaran dan ditambah dengan pendalaman materi.

Otonomi pendidikan disambut baik oleh lembaga pendidikan swasta dengan membenahi keadaan yang telah ada dengan tujuan untuk meningkatkan kualitas pendidikan, disamping itu juga adanya kebutuhan masyarakat yang disebutkan dengan tugas pekerjaan keseharian dan menginginkan pendidikan yang berkualitas, keadaan semacam ini direspon dengan menyelenggarakan model pembelajaran full day school, dalam arti kegiatan belajar mengajar diperpanjang sampai sore hari. Maka sebagai konsekuensi perlu adanya pengelolaan yang baik, khususnya dalam pembelajaran yang 
berhubungan dengan waktu belajar yang efektif, pengajaran terstruktur dan kesempatan untukbelajar.

Loukeris, ect. (2009: 162) menyatakan bahwa holoimero school atau all day school juga dapat dikatakan sebagai full day school memiliki tujuan pelaksanaan pendidikan yang dijelaskan sebagai berikut:

The basic targets of the operation of the holoimero school are as follows, The reinforcement of knowledge and skills that students are taught in the morning syllabus (study, additional teaching interventions in Language and Mathematics, consolidating teaching, individualised programmes by the schoolteachers of the afternoon classes); and the enrichment of the morning syllabus with more subjects of particular cultural and social importance (English Language, Sports, Music, Dance, Theatrical Studies, Arts, New technologies in Education), according to the students' needs and interests, taught by specialised teachers.

Hal tersebut menjelaskan bahwa tujuan pelaksanaan pendidikan holoimero school adalah untuk menguatkan pengetahuan dan keterampilan siswa (belajar, intervensi mengajar tambahan bahasa dan matematika, mengajar konsolidasi, program individual oleh guru sekolah dari kelas sore). Selanjutnya, adanya pengayaan materi pokok dengan mata pelajaran yang dikhususkan pada budaya dan sosial (bahasa Inggris, olahraga, musik, tari, studi teater, seni, teknologi baru dalam pendidikan), sesuai dengan kebutuhan dan minat siswa serta diajarkan oleh guru khusus.

Menurut Moch. Romli (2004:

karakteristik yang paling mendasar dalam model pembelajaran Full day school yaitu proses Integrated curriculum dan integrated activity yang merupakan bentuk pembelajaran yang diharapkan dapat membentuk anak (siswa) yang berintelektual tinggi yang dapat memadukan aspek keterampilan dan pengetahuan dengan sikap yang baik dan Islami. Sekolah yang menerapkan pembelajaran full day school, dalam melaksanakan pembelajarannya bervariasi, baik ditinjau dari segi waktu yang dijadwalkan maupun kurikulum lembaga atau lokal yang digunakan, pada prinsipnya tetap mengacu pada penanaman nilai-nilai agama dan akhlak yang mulia sebagai bekal kehiduapan mendatang disamping tetap pada tujuan lembaga berupa pendidikan yang berkualitas.

Baharudin (2010: 224) menyatakan bahwa sekolah yang bersistem full day school tidak hanya berbasis sekolah formal, namun juga informal. Sistem pengajaran yang diterapkan sangat menyenangkan (tidak kaku dan monoton). Guru dituntut untuk kreatif dan inovatif sedangkan siswa diberi keleluasaan untuk memilih tempat belajar. Full day school identik dengan permainan, tujuannya agar proses belajar mengajar penuh dengan suasana kegembiraan. Sekolah yang menerapkan full day school dapat menciptakan situasi yang sangat menyenangkan serta mewujudkan keakraban antar siswa dan guru yang nantinya melahirkan generasi cerdas intelektual serta emosional.

Berdasarkan paparan pendapat di atas, dapat disimpulkan bahwa karakteristik full day school adalah mengedepankan akhlak dan prestasi akademik, memperhatikan kegiatan ekstrakurikuler, sistem pengajarannya sangat menyenangkan, tenaga pengajar terdiri dari guruguru bidang studi yang profesional, menggunakan kurikulum terpadu serta 
memberikan pengalaman belajar yang luas pada anak.

Pelaksanaan full day school merupakan salah satu alternatif untuk mengatasi berbagai masalah pendidikan, baik dalam prestasi maupun dalam hal moral atau akhlak. Dengan mengikuti full day school, orang tua dapat mencegah dan menetralisir kemungkinan dari kegiatan-kegiatan anak yang menjerumus pada kegiatan yang negatif.

Ada tiga alasan yang melandasi lahirnya sistem pembelajaran full day school menurut Sutratinah Tirtonegoro (1989: 23). Pertama, mengurangi pengaruh negatif dari luar pada anak usai sekolah. Kedua, rentan waktu belajar di sekolah relatif lebih lama sehingga memaksa siswa belajar mulai pagi hingga sore hari, sehingga waktu belajar di sekolah lebih efektif dan efisien. Ketiga, sangat membantu orang tua siswa terutama yang sibuk bekerja.

Menurut Muhammad Seli (2009: 62 - 63) full day school memiliki dua tujuan yang mendasar. Pertama, mengembangkan mutu pendidikan. Kedua, salah satu upaya pembentukan akidah dan akhlak siswa dan menanamkan nilai-nilai positif. Ketiga, memberikan dasar yang kuat dalam belajar pada segala aspek yaitu perkembangan intelektual, fisik, sosial dan emosional. Sukur Basuki (2008: 5) mengemukakan bahwa dalam rangka memaksimalkan waktu luang anak-anak agar lebih berguna, maka diterapkannya sistem full day school dengan tujuan pembentukan akhlak dan akidah dalam menanamkan nilai-nilai yang positif, mengembalikan manusia pada fitrahnya yaitu sebagai klalifah fil ardhi dan sebagai hamba
Allah, dan juga memberikan dasar yang kuat dalam belajar di segala aspek.

Berdasarkan paparan di atas tentang tujuan dari full day school, dapat disimpulkan bahwa tujuan pelaksanaan full day schoolada dua tujuan utama. Pertama adalah memberikan dasar yang kuat terhadap siswa dan kedua adalah untuk mengembangkan minat dan bakat serta meningkatkan kecerdasan siswa dalam segala aspeknya.

Program full day school ini memberikan banyak keuntungan secara akademik pada siswa. Lamanya waktu belajar juga merupakan salah satu dari dimensi pengalaman anak. Full day school menunjukkan bahwa siswa akan memperoleh banyak keuntungan secara akademik dan sosial. Penerapan full day school di sekolah menunjukkan bahwa anak-anak akan lebih banyak belajar daripada bermain, karena adanya waktu terlibat dalam kelas, hal ini mengakibatkan produktifitas anak tinggi, maka juga lebih mungkin dekat dengan guru, siswa juga menunjukkan sikap yang lebih positif, karena tidak ada waktu luang untuk melakukan penyimpangan sosial karena seharian siswa berada di kelas dan berada dalam pengawasan guru.

Menurut Nor Hasan (2006: 114 - 115) dalam Jurnal Tadris mengemukakan bahwa sistem full day school memiliki beberapa keunggulan atau kelebihan dalam penerapannya. Pertama, sistem full day school lebih memungkinkan terwujudnya pendidikan utuh karena melalui pola full day school tendensi ke arah penguatan pada sisi kognitif saja dapat lebih dihindari, dalam arti aspek afektif siswa dapat 
lebih diarahkan demikian juga pada aspek psikomotoriknya. Kedua, sistem full day school lebih memungkinkan terwujudnya intensifikasi dan efektivitas proses edukasi sehingga siswa lebih mudah diarahkan dan dibentuk sesuai dengan misi dan orientasi lembaga bersangkutan, sebab aktivitas siswa lebih mudah terpantau karena sejak awal sudah diarahkan. Ketiga, sistem full day school merupakan lembaga yang terbukti efektif dalam mengaplikasikan kemampuan siswa dalam segala hal mencakup semua ranah baik kognitif, afektif maupun psikomotorik dan juga kemampuan bahasa asing.

Baharudin (2010: 225) menyatakan bahwa full day school memiliki keunggulan dan beberapa nilai tambah. Pertama, anak memperoleh pendidikan umum antisipasi terhadap perkembangan ilmu pengetahuan. Kedua, Anak mendapatkan pendidikan kepribadian yang bersifat antisipatif terhadap perkembangan sosial budaya. Ketiga, Potensi anak tersalurkan melalui kegiatan ekstrakurikuler yang diadakan sekolah. Keempat, Potensi anak tersalurkan melalui kegiatan ekstrakurikuler yang diadakan sekolah. Sedangkan Cryan dan Others (dalam Iwan Kuswandi, 2013: 54) menyatakan bahwa full day school memberikan efek positif karena anak-anak akan lebih banyak belajar dari pada bermain yang bermuara pada produktivitas tinggi, siswa menunjukkan sikap yang lebih positif, terhindar dari penyimpangan karena seharian berada di kelas dan dalam pengawasan guru.

Berdasarkan beberapa paparan pendapat ahli di atas, dapat disimpulkan bahwa keunggulan dari full day school yaitu anak memperoleh pendidikan umum antisipasi terhadap perkembangan ilmu pengetahuan, anak mendapatkan pendidikan kepribadian yang bersifat antisipatif terhadap perkembangan sosial budaya, anak mendapatkan pendidikan utuh meliputi tiga bidang yakni kognitif, afektif, psikomotorik, terwujudnya intensifikasi dan efektivitas proses edukasi sehingga siswa lebih mudah diarahkan dan dibentuk, anak-anak akan lebih banyak belajar dari pada bermain yang bermuara pada produktivitas tinggi, serta potensi anak tersalurkan melalui kegiatan ekstrakurikuler yang diadakan sekolah.

Penelitian yang telah dilakukan oleh Lee, dkk (2006) menyimpulkan bahwa pada anak usia dini di TK Amerika Serikat tahun 1998-1999 menunjukkan bahwa program full day school lebih unggul dari half day school. Bidang akademik yang paling banyak digunakan dalam pembelajaran full day school adalah membaca, berhitung dan keterampilan. Dalam pembelajaran membaca dan berhitung full day lebih unggul dari half day, dan salah satu penyebabnya adalah banyaknya waktu bersama antara anak dan guru. Hal tersebut menunjukkan bahwa full day school lebih baik dan unggul dibandingkan dengan half day school.

Penelitian lain dilakukan oleh Chloe R. Gibbs (2004) dalam EdPolicyWorks dari University of Virginia menyatakan bahwa full day memiliki efek positif terhadap siswa TK jika dibandingkan dengan half day di sekolah yang sama. Hal ini terlihat bahwa siswa TK pada full day school lebih mendapatkan efek besar dan positif terkait dengan pemahaman dalam kemampuan membaca dan keterampilan yang 
lain dibandingkan dengan half day school. Hasil tersebut menunjukkan bahwa full day school lebih berefek positif dibandingkan dengan half day school.

Penelitian berikutnya dilakukan oleh Nemitz (2015) menyimpulkan bahwa untuk ibu dengan anak-anak usia sekolah dasar di Jerman (tidak termasuk Bavaria) memiliki efek positif secara signifikan dari program sekolah dasar full day school pada penawaran tenaga kerja di margin yang luas. Rata-rata, para ibu yang memanfaatkan program sekolah dasar full day school lebih mungkin untuk dipekerjakan daripada ibu yang tidak memanfaatkan program ini. Penelitian tersebut memperlihatkan bahwa ibu/orang tua yang memanfaatkan full day school akan mudah diterima dalam bekerja dibandingkan dengan yang tidak berarti full day school memiliki banyak manfaat termasuk pada orang tua yang bekerja.

Penelitian internasional lainya dilakukan oleh Gkoratsa (2013) mengungkapkan bahwa penerapan full day school di Yunani belum maksimal terkait peraturan dan pelaksanaan prakteknya di sekolah. Pencapaian tujuan dalam full day school di Yunani meliputi tujuan paedagogis tertentu dan tujuan sosial, dalam prakteknya tujuan sosial sudah tercapai sedangkan tujuan paedagogis masih belum tercapai maksimal. Hasil penelitian tersebut terlihat bahwa penerapan full day school di Yunani sudah berjalan namun belum seluruh tujuan pelaksanaannya belum tercapai secara maksimal

Penelitian dari dalam negeri dilakukan oleh Anissa Nurul Azizah (2014) mengungkapkan bahwa pada full day school kegiatan intrakurikuler yang terintegrasi melalui mata pelajaran dan muatan lokal dalam pengembangan kemandirian siswa dilaksanakan melalui tugas mandiri yang dikerjakan siswa tanpa meminta bantuan dari teman, diskusi dimana siswa saling berpendapat untuk memecahkan persoalan yang diberikan oleh guru, dan eksperimen melalui percobaan yang dialami dan dibuktikan sendiri terkait persoalan yang diberikan oleh guru.Hal tersebut menunjukkan bahwa full day school memiliki manfaat positif dan berpengaruh dalam peningkatan kemandirian siswa.

Penelitian sejenis dilakukan oleh Azizah Afni Rizky (2015) menyimpulkan bahwa problematika yang sering terjadi dalam pelaksanaan pembelajaran sistem full day school diantaranya yang adalah masih ditemukan siswa yang belum mampu menyesuaikan diri dengan jam tambahan yang diberlakukan oleh sekolah dan adanya sebagian kecil siswa yang merasa kelelahan atau bosan karena seharian berada di sekolah. Penelitian tersebut menunjukkan bahwa full day school masih memiliki kelemahan dalam pelaksanaannya walaupun banyak keunggulan. Hal tersebut harus dapat diatasi oleh pengelola full day school di sekolah agar dalam pelaksanaannya dapat berjalan lancar.

Penelitian lainnya telah dilakukan oleh Umi Robi'ah Mutsana Fajrun Nisa' (2014) menyimpulkan bahwa evaluasi program full day school di MTs Negeri Ngemplak Boyolali terlihat bahwa dapat dilihat bahwa sebenarnya tidak ada perbedaan yang mendalam antara program full day school dan program reguler. Selama ini program full day school hanya berbeda dalam 
proses pembelajarannya dan tidak memiliki target yang khusus.Menurut manajemen pendidikan, model pelayanan pendidikan full day schooldi MTs Negeri Ngemplak hanya untuk meningkatkan eksistensi sekolah, tanpa memperhatikan standar-standar yang sudah ditentukan. Hasil penelitian tersebut menunjukkan bahwa full day school apabila dilaksanakan tanpa adanya tujuan dan perencanaan terkait segala hal yang dibutuhkan, maka tidak menutup kemungkinan program full day school akan tidak akan ada maknanya.

\section{SIMPULAN DAN SARAN}

Pendidikan dengan pembelajaran program full day school diharapkan menjadi alternatif yang dapat memenuhi tuntutan pendidikan di masa sekarang. Full day school adalah sekolah yang dalam pelaksanaan pembelajaran dilakukan selama sehari penuh dari pagi hingga sore dengan sebagian waktunya digunakan untuk pelajaran yang suasananya informal, tidak kaku, menyenangkan bagi siswa dan membutuhkan kreatifitas dan inovasi dari guru. Sekolah dapat mengatur jadwal pelajaran dengan bebas dan leluasa, disesuaikan dengan bobot mata pelajaran dan ditambah dengan pendalaman materi. Karakteristik full day school adalah mengedepankan akhlak dan prestasi akademik, memperhatikan kegiatan ekstrakurikuler, sistem pengajarannya sangat menyenangkan, tenaga pengajar terdiri dari guru-guru bidang studi yang profesional, menggunakan kurikulum terpadu serta memberikan pengalaman belajar yang luas pada anak. Full day school bertujuan memberikan dasar yang kuat terhadap siswa dan untuk mengembangkan minat dan bakat serta meningkatkan kecerdasan siswa dalam segala aspeknya. Beberapa hasil penelitian menunjukkan bahwa program full day school memiliki pengaruh yang positif dan signifikan terhadap peningkatan karakter, moral, akhlaq, maupun prestasi akademik siswa baik tingkat dasar, menengah, maupun atas.

Diharapkan sekolah di Indonesia dapat merancang dan merencanakan program full day school dalam sistem pengelolaan pembelajaran di sekolah baik dasar, menengah, dan atas. Pelaksanaan full day school harus sesuai dengan arahan dari Mendikbud yaitu sekolah tidak memberikan tambahan pelajaran bagi anak. Namun, pemberian jam tambahan untuk kegiatan ekstrakurikuler. Misalnya, keterampilan, budi pekerti, olahraga, seni budaya dan lainnya. Pemerintah diharapkan memberikan fasilitas penunjang program full day school di sekolahsekolah negeri agar pelaksanaannya berjalan lancar sesuai dengan peraturan yang ada.

\section{DAFTAR PUSTAKA}

Anissa Nurul Azizah. (2014). Program Full Day Schooldalam Pengembangan Kemandirian Siswa Kelas IV di SDIT Insan Utama Bantul Tahun Ajaran 2013/2014. Skripsi. UNY Yogyakarta

Azizah Afni Rizky. (2015). ProblematikaPembelajaran Sistem Full Day School Siswa Kelas 1 SDIT Al-IrsyadTegal. Skripsi. UNS Surakarta.

Baharuddin. (2010). Pendidikan dan Psikologi Perkembangan. Jogjakarta: Ar-Ruzz Media.

Echols, John M. \& Hassan Shadily. (1996). Kamus Inggris-Indonesia. Jakarta: Gramedia Pustaka Utama.

Gibbs, Chloe R. (2014). Experimental Evidence on Early Intervention: The Impact of Full-day Kindergarten. EdPolicyWorks Working Paper SeriesUniversity of Virginia No. 34. 
Gkoratsa, Ailina. (2013). The Impact of Greek AllDay School on Teachers, Students, and Parents Lives. Desertasi. Brunel University West London.

Lee, Valerie E., et. al. (2006). Full-Day versus HalfDay Kindergarten: In Which Program Do Children Learn More?. American Journal of Education, Vol. 112 (2).

Loukeris, Dionisios, et al. (2009). Aspect of the Effectiveness of the Greek Holoimero ('All Day') Primary School. Mediteranean Journal ofEducational Studies. Vol. 14 (2)

Moch. Romli. (2004). Manajemen Pembelajaran di Sekolah Dasar Full Day School. Disertasi. UM Malang.

Muhammad Seli. (2009). Metode Pembelajaran Pendidikan Agama Islam dalam Full Day School di Sekolah Alam Bilingual Madrasah Tsanawiyah Surya Buana Lowokwaru Malang. Skripsi. UM Malang.

Nemitz, Jenina. (2015). The Effect of All-Day Primary School Programs on Maternal Labor Supply. ECON Working Paper SeriesUniversity of Zurich No. 213
Nor Hasan. (2006). Full Day School Model Alternatif Pembelajaran Bahasa Asing. Jurnal Tadris Vol. 1 (1).

Sutratinah Tirtonegoro. (1989). Anak Super Normal dan Pendidikannya. Jakarta: Bumi Aksara.

Umi Robi'ah Mutsana Fajrun Nisa'. (2014). Evaluasi Program Kelas Full Day School di MTs N Ngemplak Boyolali Tahun Pelajaran 2013/2014. Skripsi. UNS Surakarta.

Iwan Kuswandi. (2012). Full Day School dan Pendidikan

Terpadu.http://iwankuswandi.wordpress.com/20 $\underline{12 / 07 / 09 / f u l l-d a y-s c h o o l}$ dan pendidikanterpadu/. Diakses Pada tanggal 16 Agustus 2016 pukul 09.09 WIB.

Sismanto. (2007). Menakar Kapitalisasi Full Day School.http://mkpd.wordpress.com/2007/05/21/ menakar-kapitali-sasi-“full-dayschool"\%. Diakses pada tanggal 17 Agustus 2016 pukul 10.37 WIB.

Sukur Basuki. (2007). Full Day School Harus Proporsional Sesuai Jenjang dan Jenis Sekolah.http://smkn1lmj.sch.id/dl/fuldayschool.p df Diakses pada tanggal 15 Agustus 2016 pukul 18.58 WIB. 